\title{
MEMORIAL SOBRE A TRAJETÓRIA ESCOLAR BÁSICA DE WALDEMIR ALVES
}

\author{
Waldemir Alves ${ }^{1}$
}

Resumo: O presente texto trata do memorial sobre a trajetória escolar Waldemir Alves, exintegrante do Programa Conexões de Saberes. Tem como objetivo apresentar os passos percorridos desde o início da educação básica até a entrada à UFPA e quais os principais entraves de estudantes das comunidades populares adentrarem o ensino superior público. A memória foi usada como principal referência para construção do material. Em seus resultados, apresenta os esforços individual e coletivo para que de fato a educação seja uma questão de direito e não de privilégio de poucos.

Existe uma força maior e mais potente que uma explosão atômica: a vontade.

(Albert Einstein)

Um menino e muitos sonhos:

Viver

Crescer

Voar

Ser livre e construir,

Um cantinho pra sonhar.

E encontrar alguém e um lugar tranqüilo,

Ser feliz, e só amar, amar, amar...

(Waldemir Samuel)

$\mathrm{O}$ ato de rememorar é muito importante porque traz à tona lembranças adormecidas, revive sonhos e desejos, mostra quantas dores e feridas temos ainda abertas e outras já cicatrizadas. Os sonhos são as forças motrizes que movem e alimentam as chamas e as esperanças em nossas vidas. O homem não vive sem sonho e eu, hoje com vinte e cinco anos, estudante da Universidade Federal do Pará (UFPA), Campus Castanhal, e bolsista do Programa Conexões de Saberes, tenho a oportunidade e a satisfação de contar em poucas palavras meus sonhos e a minha belíssima caminhada de vida que, sem dúvida, é igual à história de vida de muitos brasileiros.

Nada é tão simples, frágil e profundo como a vida.

\footnotetext{
1 Acadêmico* de Licenciatura em Letras da Universidade Federal do Pará Campus Castanhal, e-mail: samuk_let06@yahoo.com.br

* atualizado pela última vez em 2008.
}

Revista PET Interdisciplinar e Programa Conexões /UFPA On-line. Ed. Especial - 2017, BELÉM/ PA - ISSN 2447-097X 
Tudo começou com minha querida genitora, Antonia Alves, quando, cansada de sofrer maus tratos do seu primeiro esposo como passar fome, ser violentada física e psicologicamente, resolveu fugir da "ditadura", deixá-lo no Estado do Ceará e vir tentar uma vida nova, com seus três filhos, aqui no Estado do Pará.

Minha linda mãe hoje conta, emocionada, o quanto foi difícil a chegada nesse Estado, a saudade dos familiares que ela deixou, e lamenta com muita tristeza não ter reencontrado mais meus avós em vida. Tempos difíceis, início da década de 1980, minha mãe desempregada, sem casa para morar, três crianças pequenas para criar e outras inúmeras dificuldades para vencer, entre elas, o preconceito que sofria por ser mãe solteira.

Minha futura família - mamãe e meus três irmãos - veio morar em Apeú, uma vila do município de Castanhal $^{2}$, no Estado do Pará, onde em um momento sublime meus pais se encontraram. Foi lindo, o amor aconteceu! Desse amor eu nasci, depois, meus outros dois irmãos. Ficamos juntos pouco tempo, lamento, um amor tão bonito durou apenas seis anos, porque meu pai separou-se de nós e foi morar com outra família. Fiquei órfão de "pai vivo" aos cinco aninhos, que tristeza!

A tristeza de não ter a figura paterna presente em minha vida é uma ferida difícil de cicatrizar. Mais difícil que suportar a dor da perda de um pai foi, sem dúvida, ver nossas infâncias dilaceradas, tendo muitos trabalhos para realizar e ajudar nossa família a ter o que comer e pouquíssima oportunidade de sermos crianças, porque desde muito pequenos tivemos responsabilidades de gente grande. Minhas irmãs e minha mãe trabalhavam como empregadas domésticas, enquanto os meninos vendiam coxinha e picolé, reparávamos bicicletas na feira e limpávamos quintais para ajudar nas despesas de casa. Lamento ter começado a trabalhar muito criança, pois o trabalho que realizava tomava o tempo em que eu podia estar brincando de futebol, peteca, empinando pipa e tantas outras brincadeiras boas, as quais recordo com certo carinho. Recordo que muitas vezes ficava observando as outras crianças brincando, enquanto nas mãos, eu tinha a responsabilidade de levar dinheiro para ajudar a comprar "o pão de cada dia".

(...) $\mathrm{O}$ mundo todo abarco e nada aperto. (...) Numa hora acho mil anos, e é de jeito Que em mil anos não posso achar uma hora (...).

(Camões)

\footnotetext{
${ }^{2}$ Castanhal é uma cidade do nordeste paraense, localizada a $66 \mathrm{Km}$ da capital, Belém.
}

Revista PET Interdisciplinar e Programa Conexões /UFPA On-line. Ed. Especial - 2017, BELÉM/ PA - ISSN 2447-097X 
Com muita coragem e vontade de vencer na vida enfrentei as dificuldades que a sociedade proporcionava, ainda mais para quem é negro e pobre. Apesar dos obstáculos, ao meu lado sempre esteve alguém admirável como um super-herói: "mamãe”. A super-mamãe é a mulher mais fantástica do mundo! Pois, com carinho e muito amor criou, educou e incentivou todos nós, seus filhos. Ela pouco estudou, só a primeira série do ensino fundamental, mas aprendeu com a maior escola: “a vida'. Virtudes essenciais ao ser humano como honestidade, solidariedade e respeito, hoje infelizmente "privilégio" de poucos, foi a dona "Antonia" quem nos ensinou.

Meu currículo de trabalho é invejável a qualquer adulto, mas não diria a uma criança. Não me lembro qual a idade em que comecei trabalhar, porém até os doze anos já havia trabalhado em diversas atividades. Ficava triste quando encontrava alguém que comia as coxinhas e tomava os picolés e não queria pagar. Entretanto, enchia-me de alegria, a qual era compartilhada com minha família, quando vendia os picolés e as coxinhas e chegava em casa com algum dinheiro para ajudar nas despesas.

Para algumas correntes psicológicas nós somos fruto do meio.

As interações sociais são importantíssimas para formação da personalidade do sujeito. A escola, como lugar de interações, local onde o indivíduo passa doze anos de sua vida, contribui de maneira decisiva na formação do caráter das pessoas. A escola foi e é um ambiente de importantes encontros e descobertas. Nela descobri o universo encantado das letras e dos números, fiz grandes e preciosos amigos que muito me ajudaram, descobri novos amores e vivi intensas paixões! Algumas dessas paixões foram minhas professoras; eu sentia falta da atenção e do amor que mãe quase não me transmitia, pois ela estava sempre ocupada trabalhando, então transferia o amor que tinha por mamãe às minhas queridas professoras. Aos sete anos de idade fui inserido no ambiente escolar, e em minha primeira escola estudei da alfabetização à segunda série. Tenho boas memórias desse período: a brincadeira de roda com os amigos, a música "Terezinha de Jesus", Hino Nacional, o corre-corre típico da criançada... Ah! Eu adorava correr e fantasiar que era um super-herói.

Numa sociedade capitalista como a nossa, o trabalho é muito importante para uma pessoa adulta, "talvez aceitável para os adolescentes em idade escolar, mas deplorável às crianças". Nessa sociedade ser alguém pobre e negro se apresenta como a condição fatalística de inferioridade. Hoje, tenho coragem de me autodeclarar negro e pobre e não mais um 
"pobre negro, o coitado. Sei que não sou melhor nem inferior a ninguém, no entanto, sou o que são meus pensamentos. Acredito que o saber é meu maior tesouro e a educação frente a nossa indigência e a melhor maneira de vencermos uma triste realidade.

A pobreza material nos privou de muitas coisas boas. Em casa a comida era pouquíssima, tomávamos café com farinha ${ }^{3}$, pois não tínhamos dinheiro para comprar pão. Carne ou galinha, quando tinha, era aos domingos e só dois pedaços e nada mais. Minha fantástica mãe ao final do mês, quando ela recebia, comprava um pacotinho com seis biscoitos recheados e eu dividia com meus dois irmãos mais novos. Lembro-me que meu maior desejo era crescer e conseguir um emprego para poder comprar "biscoito recheado", porque comer biscoito recheado frente a quem tomava diariamente café com farinha era muito melhor.

Muitas outras lembranças não consigo rememorar, estão reprimidas em meu inconsciente, talvez por serem dolorosas demais. Recordo-me que morávamos de aluguel em uma vila, a situação era tão difícil que o sonho de mamãe era ter uma "cama", sim, uma cama! Sonhar com uma casa própria era um sonho quase impossível. Nesse período houve uma invasão perto do local onde nós morávamos, conseguimos um terreno e construímos nossa primeira casa. Minha mãe conseguiu um emprego de servente no quartel do Corpo de Bombeiros, saía de casa as 05h e só retornava quando o sol se punha. Depois de alguns anos, conseguiu transferir-se e foi trabalhar na mesma função numa escola durante a noite. Essa escola ficava longe de onde nós morávamos e o caminho era tão perigoso que mamãe foi assaltada, então trocou o nosso lar por uma outra casa perto do seu local de trabalho.

Esse novo local de trabalho da mamãe se tornou minha nova escola. Logo tornei-me um dos alunos mais comportados da escola, claro, a dona Antonia trabalhava lá e eu tinha medo de apanhar dela! Eu estudava em um horário e nos outros vendia coxinha e pipoca nos intervalos do recreio. Nessa escola estudei a $3^{\text {a }}$ e a $4^{\text {a }}$ série, fui um bom aluno e fiz grandes amigos. Ainda estão nítidas em meu pensamento as imagens daquele garotinho magro e tímido que, apesar da timidez e da vergonha, queria ser diferente; queria talvez estar na mesma condição de alguns amigos e ter, assim como eles, algum dinheiro pelo menos para comprar um saquinho de pipocas. É algo paradoxal vender pipoca aos outros e não ter dinheiro para comprar uma para eu comer. O dinheiro que arrecadava era para ajudar na feira de casa, não para realizar os meus desejos infantis.

${ }^{3}$ Farinha é um alimento extraído da mandioca e faz parte da alimentação diária do paraense

Revista PET Interdisciplinar e Programa Conexões /UFPA On-line. Ed. Especial - 2017, BELÉM/ PA - ISSN 2447-097X 
$\mathrm{Eu}$ queria ser "igual" àqueles amigos: ter dinheiro para comprar "pipoca e o tão desejado biscoito recheado". Certa vez, quando eu estudava a $4^{\text {a }}$ serie "peguei escondido o dinheiro" que a mamãe tinha guardado para comprar comida, ela sentiu falta dele; incrível, não me bateu, todavia conversamos. $\mathrm{O}$ poder de suas palavras doeram muito mais que todas as "pisas"4 juntas, as quais eu já havia pegado, e pela primeira vez, choramos juntos! Mamãe aconselhou-me e explicou-me que se eu tivesse gastado aquele dinheiro deixaria nossa família sem ter o que comer, então pediu para eu não fazer mais aquilo. Esse fato foi uma lição de vida.

Um dia um rapazinho Mas que se considerava um menino

Percebeu sua infância pobre

Queria se tornar nobre

E brincar como criança.

Pegou sua infância pobre

E aprendeu a amar a vida

Mesmo sendo ela sofrida

E a inundou com esperanças nobres.

(Waldemir Samuel)

Nosso contexto social era difícil, pois morávamos numa periferia com elevado índice de violência, venda de drogas, constantes roubos e freqüentes assassinatos. Vivíamos com os nervos sobressaltados porque estávamos vulneráveis a qualquer momento sofrer algum tipo de violência. Recordo o dia que em frente à minha casa um rapaz levou um tiro no meio do peito e ficou agonizando com um revólver na mão, até falecer. Em outro dia quando eu ia para escola, pela manhã, escutei disparos de tiros e pensava que fossem foguetes, porém, infelizmente, não eram. Encontrei na esquina, caído dentro da vala, mais um cidadão morto, e na noite anterior a esse fato o esposo da minha professora tinha sido assassinado dentro de sua casa, também com vários tiros.

Infelizmente, perdi alguns amigos para a criminalidade. Lamento muito! Entrar para o mundo obscuro da criminalidade é muito fácil. Os criminosos se aproveitam da própria condição de miséria do povo e seduzem crianças, jovens e até adultos com promessas de dinheiro fácil, e com alguns amigos não foi diferente. Acredito que se eles tivessem tido outras oportunidades como, por exemplo, conhecer o universo encantado da leitura e da escola, teriam uma vida diferente. Tive todas as possibilidades de ser seduzido pela 4 "Pegar uma pisa": surra, caracterizada pela mãe do indivíduo (Disponível em: http://www.braganca.pa.gov.br/dic_pa.htm)

Revista PET Interdisciplinar e Programa Conexões /UFPA On-line. Ed. Especial - 2017, BELÉM/ PA - ISSN 2447-097X 
criminalidade e fui; influenciado pelos meus amigos cheguei até a experimentar drogas, no entanto, mais uma vez minha preciosa mãe interferiu em minha ida e mostrou-me que a criminalidade não era, nem é, o caminho o qual nos leva à felicidade, e em face a tudo isso, a escola e a educação tornaram-se a possibilidade de mudança e de um futuro melhor para mim e para minha família.

Se eu pudesse, falaria só sobre meu único ídolo: minha mãe. Contudo, isso fica para um outro momento. Ela, apesar do pouco estudo, sempre incentivou seus filhos a estudar e sonhava vê-los concluir o segundo grau. Assim, meus estudos foram, até o segundo grau, voltados para realizar o sonho que não era meu, mas de minha mãe. Por ter iniciado a vida profissional muito pequeno, na idade e na estatura, não tinha tempo reservado para ser criança - brincar, correr, pular - parece paradoxal, no entanto era o que acontecia: pela manhã tinha que trabalhar, a tarde estudava e a noite vendia coxinha aos alunos da escola. Porém, eu sempre dava um jeitinho e às vezes fugia para jogar futebol.

Trabalhar enquanto criança não foi uma escolha minha, mas uma necessidade de sobrevivência. Nossas vendas não estavam mais dando lucro e algo que marcou minha vida foi quando em um dia de sábado minha mãe pediu para eu e o meu irmão Valnei pegarmos uma enxada e pediu que fôssemos procurar um quintal para capinar. Quando encontramos um trabalho já era $11 \mathrm{~h}$. Pedi três reais pela capinação, o meu irmão achou o preço pelo trabalho muito baixo. Pelo meio-dia choveu, e a chuva veio amenizar o calor do sol e somar-se ao nosso suor. Ao terminarmos o serviço, o pouco dinheiro recebido foi recompensado com um bom prato de feijão, arroz, peixe e a amizade de dona Lusia, a proprietária da casa. Esse trabalho foi abençoado e abriu as portas para outros. No entanto, foi necessário me acostumar a essa dupla jornada de trabalhador e estudante. Tive o privilégio de encontrar em minha vida pessoas como seu Brás, irmão da dona Lusia, uma "espécie" de paizão que me ensinou coisas maravilhosas.

Se tinha que trabalhar, fui à luta, e na casa do seu Brás trabalhei como ajudante de pedreiro, pintor e jardineiro. Logo após esses trabalhos surgiu uma vaga de garçom em uma churrascaria onde minha irmã, Valdenisa, trabalhava pela manhã. Eu estava apenas com quatorze anos, mas aceitei com alegria o novo emprego. O emprego era legal, eu trabalhava de segunda-feira a sábado, entrava às $16 \mathrm{~h}$ e não tinha horário para sair. Recordando esses sentimentos, lembro o quanto foi doloroso trabalhar na churrascaria, porque as minhas tardes e as seguidas noites pareciam mais uma prisão. Inúmeras vezes me senti como um passarinho engaiolado e eu só queria voar, voar, voar... Sentir a brisa do fim das tardes em meu rosto e 
ver o pôr-do-sol, e não a quentura do fogo que vinha da churrasqueira. Esse foi um dos trabalhos mais difíceis que já enfrentei, pois além de tudo isso, dormia muito tarde e acordava cedo para ir à escola porque estudava pela manhã.

Há entre o tempo e o destino

Um caso antigo um elo um par

Que pode acontecer menino

Se o tempo não passar (...).

(...) O tempo é quem me deu amigos

E esse amor que não me sai (...).

(Nilson Chaves/Vital Lima)

E se não lutarmos pela vida, o que será de nós? Tive muitos motivos para desistir dos estudos, entretanto, esses motivos só me ajudaram a perceber que seriam os estudos que me tirariam dessa situação. Mudaram com a churrascaria para o centro da cidade, então ficou muito longe da minha casa e resolvi trabalhar como padeiro. Como já estava acostumado a passar sono não foi difícil me adaptar à nova função. Passei a estudar no turno da tarde, acordava todos os dias no melhor do sono, às 04:30h, para arrumar os pães e sair para entregálos. Quando retornava das entregas, ia à feira comprar material e trabalhava até às 12:00h, almoçava e ia à escola e, ao retornar, ia direto à panificadora trabalhar até às 22:00h.

A $5^{\text {a }}$ série, para mim, foi a mais difícil. Fui estudar numa escola que ficava muito longe da minha casa, e enquanto na $4^{\mathrm{a}}$ série havia apenas um professor, na $5^{\mathrm{a}}$ série havia vários. Pela primeira vez fiquei em recuperação, foi na disciplina de Estudos Amazônicos, entretanto, passei. $\mathrm{Na} 6^{\mathrm{a}}$ série uma das primeiras aulas foi de Matemática, a professora se chamava Dalva. Ela perguntou qual era a disciplina a qual eu achava mais difícil, talvez ela esperasse ouvir Matemática, porém eu adorava essa matéria, então respondi Estudos Amazônicos, porque foi a única disciplina a qual fiquei para recuperação. A turma quase toda riu! Conclui a $6^{\mathrm{a}}$ série sem grandes dificuldades.

O trabalho na padaria foi muito bom, lá trabalhei pouco mais de um ano. Fui convidado a trabalhar novamente na churrascaria, e por razões financeiras aceitei. Mas agora havia algumas condições, pois eu já estudava à tarde. Ficou acordado que não haveria problema se eu chegasse mais tarde nos dias que tivesse as seis aulas, que pelo horário da escola só dois dias da semana. No entanto, um desses dias, após a aula, o professor fez uma coisa maravilhosa: convidou-nos a sentar na pracinha da escola para conversarmos sobre nossos sonhos e ele incentivou-nos a lutar por eles. E quando cheguei ao trabalho fui repreendido, pois já eram 18:40.

Revista PET Interdisciplinar e Programa Conexões /UFPA On-line. Ed. Especial - 2017, BELÉM/ PA - ISSN 2447-097X 
Em um desses dias de trabalho árduo percebi que em mim, apesar de ser muito pobre, havia algo valiosíssimo e que os cem reais mensais, os quais ganhava na churrascaria, não podiam comprar: os sonhos! Foi refletindo com minha família que cheguei à conclusão: eu poderia ir muito mais longe. Comecei a sonhar com a universidade! Não sei por quê, mas, minha querida mãe sempre me deu forças em minhas decisões. Por livre vontade decidi tentar algo melhor em minha vida e pedi demissão do trabalho na churrascaria. Não me arrependo!

Um mês depois fui com um amigo pintar alguns bancos em um convento. Ao terminarmos o serviço, a Irmã responsável pela casa, pediu que eu realizasse outros trabalhos e os fiz com muito gosto. Elas gostaram do meu serviço e assinaram minha carteira de trabalho. No convento trabalhei de serviços gerais por mais de cinco anos e só deixei esse trabalho no ano passado, pois estava quase impossível conciliar o trabalho com a universidade, porque eu trabalhava muito e tinha pouco tempo para dedicar-me aos estudos.

$\mathrm{Na} 7^{\mathrm{a}}$ série fui estudar em uma escola recém-inaugurada perto de minha casa e lá estudei o restante do $1^{\circ}$ grau e todo o $2^{\circ}$. Nessa escola fiz grandes amigos e conheci maravilhosos educadores, os quais muito me ajudaram nos meus estudos e me incentivaram a lutar por meus sonhos. Em 2001 o conclui o $2^{\circ}$ grau; nossa turma fez uma bonita festa de colação de grau e a dona Antonia ficou felicíssima. Assim, fui o primeiro da família a concluir o $2^{\circ}$ grau e a realizar um dos grandes sonhos de minha mãe: "ver seus filhos formados". Infelizmente, somente eu e o Valnei conseguimos concluir o $2^{\circ}$ grau.

Como já havia realizado o sonho de minha mãe, no ano de 2003, resolvi voltar à dupla jornada de estudante e trabalhador, agora para lutar pelos meus sonhos: um deles me formar em Psicologia. Acreditem! Sim, é possível que nós, alunos de origem popular, cursemos uma universidade! Esse ano foi muito difícil porque eu entrava no trabalho às 7:00h e só retornava para casa às 17:00h, tomava banho, comia algo e caminhava trinta minutos até chegar ao cursinho pré-vestibular o qual se localizava no centro da cidade. As aulas iniciavam às 19:00h e terminavam às $22: 45 \mathrm{~h}$, e como eu acordava muito cedo e trabalhava quase o dia inteiro, à noite estava muito cansado. Recordo-me das noites que adormeci na cadeira do cursinho, mas não desisti! No final do ano prestei vestibular para entrar no curso escolhido, na Universidade Federal do Pará (UFPA), entretanto, não consegui passar.

No ano seguinte minha condição financeira não dava para pagar a mensalidade do cursinho e participei somente de um mês de revisão e, nesse ano, tentei o vestibular para Letras, porque o curso de Psicologia só há na capital, Belém, e eu não teria condições financeiras para me manter nele. Nesse ano não passei novamente, mas faltaram só três 
pontinhos. Não desisti! Em 2005 fiz um enorme sacrifício, voltei a dupla jornada - trabalho e estudos - e adormeci inúmeras noites na cadeira do cursinho! Depositei todas as minhas forças no sonho de cursar a universidade e poder ajudar minha família. Prestei vestibular para Letras e adivinha o que aconteceu? Alô papai, alô mamãe, ponha a vitrola pra tocar, podem soltar foguetes que eu passei no vestibular... ${ }^{5}$ Fogos, festa, eu passei!

Muito feliz, já estou no terceiro ano do curso de Letras; no início de 2010, formarei e irei em busca de conquistar meu maior sonho profissional: cursar Psicologia. Minha breve trajetória de vida mostra que um menino negro, pobre, filho da servente Antonia, nascido em um bairro pobre, criado em uma periferia, entretanto com a riqueza dos sonhos na alma, enfeitou seus dias com a poesia que a vida nos proporciona e viu nascer belíssimas flores de onde antes colheu muitos e dolorosos espinhos. Consegui chegar à universidade, mas minhas experiências de vida não terminam aqui, porque diariamente há um novo e lindo recomeçar. Obrigado!

\footnotetext{
${ }^{5}$ Marchinha de carnaval que faz parte da comemoração do vestibular dos novos calouros assim que recebem a notícia da aprovação.
}

Revista PET Interdisciplinar e Programa Conexões /UFPA On-line. Ed. Especial - 2017, BELÉM/ PA - ISSN 2447-097X 